\title{
Novel germline CDK4 mutations in patients with head and neck cancer
}

\author{
Maimoona Sabir, Ruqia Mehmood Baig, Ishrat Mahjabeen and Mahmood Akhtar Kayani*
}

\begin{abstract}
Background: Cyclin-dependent kinase 4 (CDK4) together with its regulatory subunit cyclin D1, governs cell cycle progression through $G_{1}$ phase. Cyclin-dependent kinase inhibitors, including $p 16^{1 \mathrm{NK} 4 \mathrm{~A}}$ in turn regulate CDK4. In particular, deregulation of the p16/CDK4/cyclin D1 complex has been established in a variety of human tumors including gliomas, sarcomas, melanoma, breast and colorectal cancer. However, changes in CDK4 have rarely been observed.

Method: In this study we used a combination of PCR-SSCP and direct sequencing for mutational screening of CDK4. DNA was isolated from peripheral blood leukocyte of patients with squamous cell carcinoma of head and neck, for screening germline mutations in coding regions of CDK4.
\end{abstract}

Results: Variations observed in exon 2 and 5 were three missense mutations, g5051G > C (Ser52Thr), g5095G > C (Glu67Gln), g5906C > A, g5907C > G (Pro194Ser) and novel frame shift mutations g7321_23delTGA, g7121_7122insG, g7143delG in exon 7 and 3/UTR respectively.

Conclusion: In conclusion, two novel mutations were found in $\mathrm{N}$ terminal domain which indicates that CDK4 mutation may play a major role in the development and progression of squamous cell carcinoma of head and neck.

Keywords: CDK4, germ line mutations, SSCP, squamous cell carcinoma of head and neck, Pakistani population

\section{Background}

Cyclin-dependent kinases $(C d k s)$ are serine/threonine kinases that regulate progression through cell cycle. CDK4 and CDK6 act early in the cell cycle and are involved in the transition from $G_{1}$ to $S$ phase [1]. Loss of $\mathrm{G}_{1}$ control in cell cycle appears to be an important step contributing to tumorigenesis [2]. D-type cyclin and their kinase partners, $C D K 4$ and $C D K 6$, coordinately phosphorylate the $\mathrm{Rb}$ protein, thereby releasing the transcription factor at $G_{1}$ and then progressions into the $S$ phase occurs [3]. In addition to role in cell cycle, there is increasing evidence that $C d k s$, as well as cyclin and cyclin-dependent kinase inhibitors are important for other cellular functions, including cytoskeleton rearrangement and cell migration [4]. CDK4 is a potential oncogene, located on chromosome 12q13; mechanisms of activation could include gene amplification, over-

\footnotetext{
* Correspondence: mkayani@comsats.edu.pk

Cancer Genetics Lab, Department of Biosciences, COMSATS Institute of Information Technology, Park Road Chak shahzad, Islamabad, Pakistan
}

expression, decreased degradation, and activating point mutations. The CDK4 is amplified and over expressed in a number of human tumors including the gliomas, sarcomas, breast tumors and colorectal carcinomas [5]. In humans, rare point mutations in the CDK4 have been described worldwide [6]. All CDK4 reported mutations are located in exon 2, which codes for the $\mathrm{p} 16^{\mathrm{INK} 4 \mathrm{~A}}$ binding site [7]. Derailments of Rb pathway caused either by lack of Rb gene (pRb1-CycinD1-Cdk4/6-p16 ${ }^{\mathrm{INK} 4}$ ) expression and over expression of $C d k s$ are implicated in the deregulation of cell cycle machinery, resulting in uncontrolled growth, tumor heterogeneity, invasion and metastasis [8].

Aim of study was to investigate a possible disruption of $\mathrm{Rb}$ suppression pathway by germline mutational analysis in the p16 binding and cyclin D1 binding domain of CDK4 in squamous cell carcinoma of head and neck in Pakistani population. Furthermore, to determine association of novel mutations in CDK4 and risk of squamous cell carcinoma of head and neck, we performed polymerase chain reaction, 
Table 1 List of primers with annealing temperature and product size (bp)

\begin{tabular}{lcccc}
\hline Exon $\mathbf{N o}$ & Primer sequence (Forward) $\mathbf{F}$ & Primer sequence (Reverse) $\mathbf{R}$ & Product size (bp) & Annealing temperature ${ }^{\circ} \mathbf{C}$ \\
\hline 1 & TCACGTGCCAGAACGTC & CTCATTCCTGGGAGGGACT & 266 & 56 \\
2 & AAGCGACTITGGTGATAGGA & TTACTCCCCACGCCCAAC & 308 & 54 \\
3 & GAGAGGCCATGTTGGTTAA & TCCACCTCTCAATGCCTACC & 222 & 58 \\
5 & TCTGGGATTCAGGTATGGTG & ATTGCTACGGGCAATCACTC & 295 & 58 \\
6 & GTGTTCATGGTAACCCATGG & TTATGAACAAGCGATTGGG & 219 & 58 \\
7 & TCTITGAAATGACTGCTACCTT & CCTGGGTCAGCAGAAAGAG & 156 & 58 \\
\hline
\end{tabular}

single strand conformation polymorphism (PCR-SSCP) and sequence analysis.

\section{Materials and methods}

Sample collection and clinical data

The present study was conducted with a prior approval from ethical committees of both department and hospitals. Blood samples from total of 380 patients with histological confirmed squamous cell carcinoma of head and neck, including oral cavity, pharynx and larynx were collected from National Oncology and Radiotherapy Institute (NORI), Pakistan Institute of Medical Sciences (PIMS) and Military Hospital (MH). A total of 350 age, gender, and ethnicity matched cancer free healthy individuals were selected as controls. Patients and controls suffering from any other familial disease (diabetes, blood pressure and cardiovascular impairment) were excluded from this study. After obtaining informed consent, all individuals were personally interviewed using a specifically designed questionnaire.

\section{DNA extraction}

Blood samples from patients and normal individuals (control), belonging to the same age and gender were collected in tubes containing EDTA and stored at $4{ }^{\circ} \mathrm{C}$. DNA was extracted from white blood cells, using standard phenol-chloroform extraction method [9,10] and stored at $-20^{\circ} \mathrm{C}$ for further processing. Electrophoresis was performed on isolated DNA in 1\% ethidiumbromide stained agarose gel and photographed (BioDoc Analyze Biometra).

\section{Polymerase chain reaction (PCR)}

Human CDK4 sequence was taken from Ensemble. Primers were designed by using PRIMER 3 INPUT SOFTWARE version 0.4.0 (Table 1). Coding regions and their exon/intron boundaries of approximately 60 bp sequence of were investigated to identify any splice site variation as well. Each PCR reaction was performed in a $20 \mu \mathrm{l}$ reaction mixture containing approximately $20 \mathrm{ng}$ of genomic DNA templates, $2 \mu \mathrm{l}(10 \mathrm{mM})$ of each primer, $0.24 \mu \mathrm{l}(25 \mathrm{mM})$ of dNTP, $2 \mu \mathrm{l}(10 \mathrm{x})$ PCR buffer and $0.2 \mu \mathrm{l}(5 \mathrm{u} / \mu \mathrm{l})$ of Taq polymerase. PCR profile consisted of an initial melting step of $94^{\circ} \mathrm{C}$ for $5 \mathrm{~min}$, 35 cycles of $94^{\circ} \mathrm{C}$ for $45 \mathrm{~s}$, annealing temperature for $1 \mathrm{~min}$ and $72^{\circ} \mathrm{C}$ for $1 \mathrm{~min}$ and a final extension step of $72^{\circ} \mathrm{C}$ for $10 \mathrm{~min}$ and hold at $4^{\circ} \mathrm{C}$.

\section{Mutational screening and sequence analysis}

Amplification products were resolved on a $2 \%$ ethidium bromide containing agarose gel along with 100 bp DNA ladder. PCR products were analyzed by single stranded conformational polymorphism (SSCP) [11] and results were analyzed with the gel documentation system (BioDocAnalyze, Biometra). Samples with an altered mobility patterns were reamplified and than analyzed by direct sequencing to confirm and characterize the nature of

Table 2 Characteristics of head and neck cancer patients

\begin{tabular}{llc}
\hline Variables & & Cases N=380 (\%) \\
\hline Gender & Male & $196(51.5 \%)$ \\
& Female & $184(48.5 \%)$ \\
Age at diagnosis & Mean ( \pm S.D) & $38( \pm 16.35)^{*}$ \\
& $<40$ & $271(71 \%)$ \\
Family history of cancer & $>40$ & $109(29 \%)$ \\
& Yes & \\
& No & $65(17 \%)$ \\
Cancer type* & & $315(83 \%)$ \\
& Oral cavity & $224(59 \%)$ \\
Smoking status* & Pharynx & $97(25.5 \%)$ \\
& Larynx & $59(15.5 \%)$ \\
& Non smokers & \\
& Smokers & $142(37.5 \%)$ \\
\hline
\end{tabular}

* Mean age, 38 years ( \pm S.D).

* Cancer type include squamous cell carcinoma of oral cavity, pharynx and larynx. 


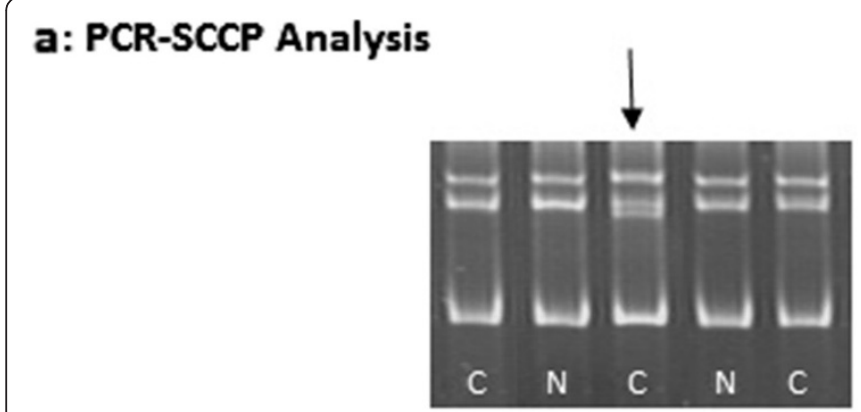

b: Sequence Analysis

A

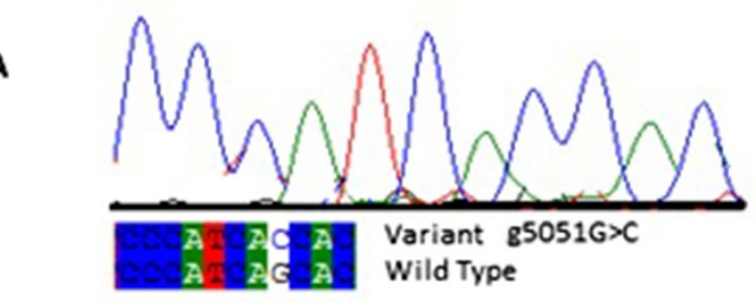

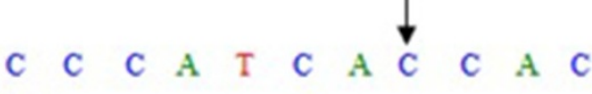

B

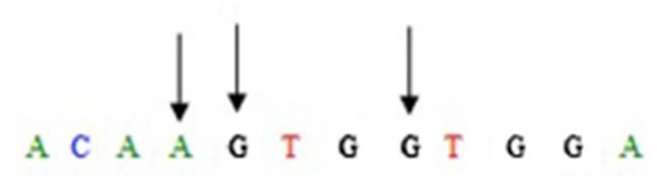

C

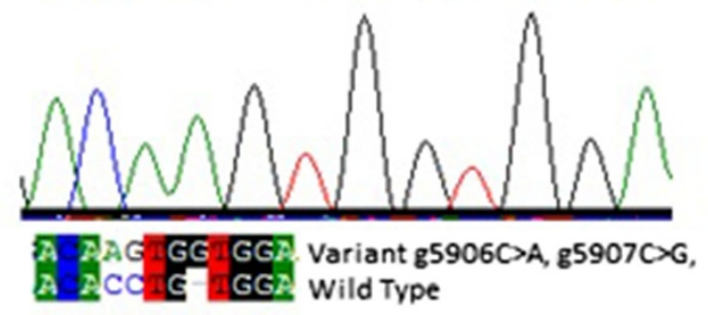

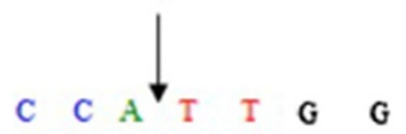

E

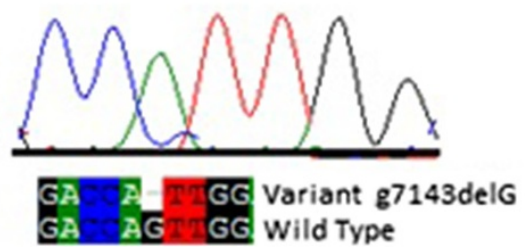

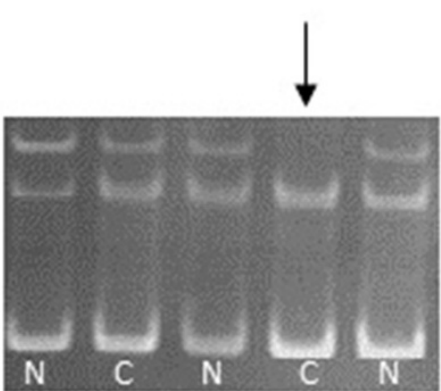
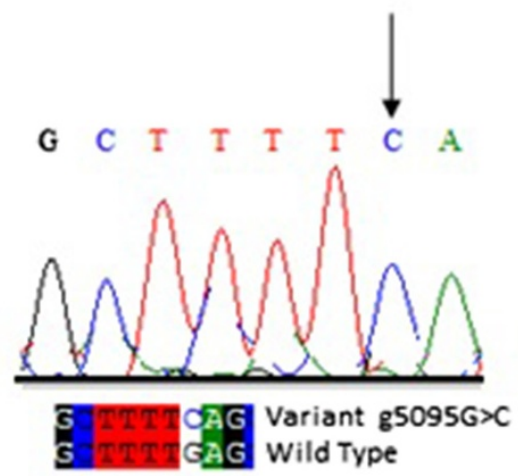

D

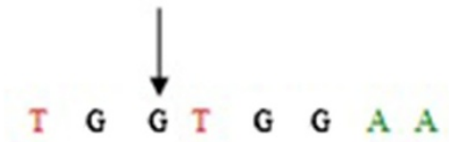

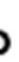

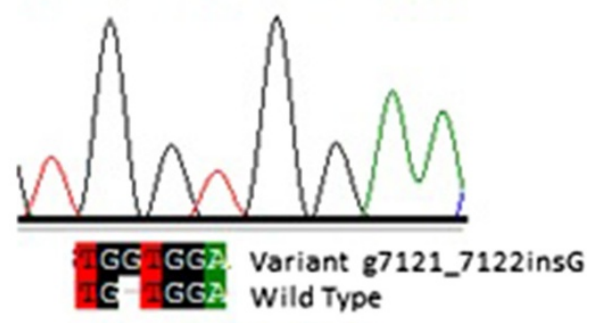

$\mathbf{F}$

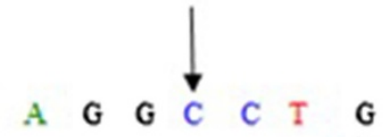

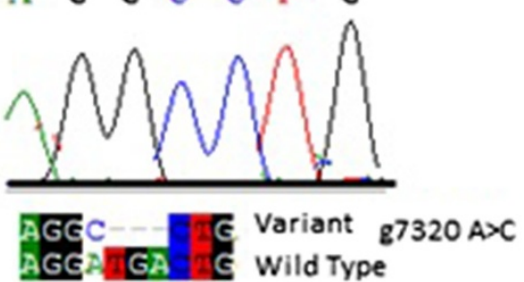


(See figure on previous page.)

Figure 1 a: Mutations in CDK4 detected by PCR-SSCP analysis in head and neck cancer samples, digital image of an ethidium bromide stained $8 \%$ non denaturing polyacrylamide gel showing band pattern. Arrow head indicates change in band shift. C represents HNC cases and $\mathrm{N}$ represents normal samples. b: Sequencing electropherogram of mutations in CDK4: (A) Missense g5051G > C mutation, (CM994495) in exon 2 showing $G$ to $C$ substitution resulting in change of DNA sequences from AGC to ACC encoding amino acid threonine instead of serine, (B) Missense mutation, g5095G > C (Novel) in exon 2 showing G to C substitution resulting in change of DNA sequence from GAG to CAG encoding the amino acid glutamine instead of glutamate, (C) Missense mutations, g5906C > A, g5907C > G in exon 5 changing the DNA sequence from CCT to AGT encoding the amino acid serine instead of proline, (D) Frame shift mutation in 3NTR as a result of insertion of nucleotide G, (g7121_7122insG), (E) Frame shift mutation in 3/UTR as a result of deletion of nucleotide G (g7143delG), (F) Missense mutation g7320A > C and frameshift mutation g7321_23delTGA in exon 7.

mutations. Sequence analysis was carried out by MCLab (USA). Control (normal) samples were also sequenced along with cases to avoid false negative results and check the quality of sequencing.

\section{Statistics and bioinformatic analysis}

$\chi 2$-test with Fisher exact test was used to evaluate the differences in selected demographic variables by using the SPSS 17.0 software, odd ratios (OR) and 95\% confidence interval $(\mathrm{CI})$ were calculated. Bioinformatic analysis for homology modeling was performed using ClustalW 2.1 multiple sequence alignment and UCSF Chimera 1.5.3 program.

\section{Results}

\section{Patient characteristics}

The features of our population are listed in Table 2. These 380 patients have mean age of 38.1 years at diagnosis. The mean age of controls $(35 \pm 12.23$ years) was slightly different from cases $(38 \pm 16.35)$, but the difference was not significant $(p<0.86)$. Statistically significant increase in incidence of head and neck cancer was observed in age group of $<40$ years as compare to age group $>40(p<0.05)$ (Table 2).

\section{PCR-SSCP and direct sequence analysis}

To investigate whether alterations of the CDK4 were present in the squamous cell carcinoma of head and neck, we screened the coding regions (exons 1-8) as well as intron/exon boundaries of CDK4 using PCR-
SSCP. Figure 1 (a \& b) summarizes the results of PCRSSCP and direct sequence analysis. In this study different types of mutations were identified in exon 2, 5, 7 and 3/UTR. No alteration in exon 1, 3, 4, 6 and 8 of $C D K 4$ was detected in any of cases.

Study revealed a reported missense mutation g5051G > C (CM994495) in exon 2 show $G$ to $C$ substitution resulting in change of nucleotide sequences from AGC to ACC, encoding amino acid threonine instead of serine. A novel missense mutation g5095G $>C$ resulting in change of nucleotide sequence from GAG to CAG, encoding the amino acid glutamine instead of glutamate. Study includes other novel missense mutations, g5906C > A and g5907C > G, in exon 5 changing the nucleotide sequence from CCT to AGT, encoding the amino acid serine instead of proline. A novel missense g7320A $>C$ mutation and a frame shift mutation g7321_23delTGA was also detected in exon 7. Two novel frame shift mutations were observed in 3/UTR as a result of insertion of nucleotide G (g7121_7122insG) and deletion of nucleotide G (g7143delG) (Table 3). No such mutation was present in control samples. Oral cavity cases have more mutation compare to pharyngeal and laryngeal carcinoma but difference was statistically non significant $[p=0.13$, OR $84.0,95 \%$ CI $(65.69$ to 233.69)]. Significant difference was observed in smokers and non-smokers patients having missense and frame shift mutations $[p=0.03$, OR $1.84,95 \%$ CI $(1.33-2.54)]$ (Table 4). To verify whether the Arg24Cys mutation in the CDK4 was present in squamous cell carcinoma, we

Table 3 Frequency of CDK4 mutations in squamous cell carcinoma of oral cavity, pharynx \& larynx

\begin{tabular}{lcccc}
\hline Region in gene & Mutations & Mutation type & Change in amino acid & Frequency of mutations \\
\hline Exon 2 & g5051G $>C^{*}$ & Missense* & Ser52Thr & 0.08 \\
Exon 2 & g5095G $>C$ & Missense & Glu67Gln & 0.13 \\
Intron 3 & g5427delA & - & - & 0.14 \\
Exon 5 & g5906C $>$ A, g5907C >G & Missense & Pro194Ser & 0.19 \\
Exon 7 & g7320 A $>$ C, g7321_23delTGA & Frame shift & - & 0.15 \\
3l UTR & g7121_7122insG & Frame shift & - & 0.16 \\
3l UTR & g7143delG & Frame shift & - & 0.09 \\
\hline
\end{tabular}

* Reported mutation with CM994495 coding unknown *http://www.ensembl.org/Homo_sapiens/Variation/Summary?db=core;g=ENSG00000135446; $\mathrm{r}=12: 58142034-58149796 ; \mathrm{v}=\mathrm{CM} 994495 ; \mathrm{vdb}=\mathrm{variation;vf=44643002}$. 
Table 4 Distribution of CDK4 mutations with area of cancer and smoking status

\begin{tabular}{|c|c|c|c|c|c|c|}
\hline \multirow{2}{*}{$\begin{array}{l}\text { Region } \\
\text { in gene }\end{array}$} & \multirow{2}{*}{$\begin{array}{c}\text { Mutations/change in amino } \\
\text { acid }\end{array}$} & \multicolumn{3}{|c|}{ Area of cancer } & \multicolumn{2}{|c|}{ Smoking status } \\
\hline & & Oral cavity $(\mathrm{N}=224)$ & Pharynx $(\mathrm{N}=97)$ & Larynx $(\mathrm{N}=59)$ & Non smoker $(\mathrm{N}=238)$ & Smokers $(\mathrm{N}=142)$ \\
\hline Exon 2 & g5051G >C & 24 & 19 & 06 & 19 & 30 \\
\hline Exon 2 & g5095G >C & 22 & 15 & 08 & 22 & 23 \\
\hline Intron 3 & g5427delA & 18 & 11 & 02 & 17 & 14 \\
\hline Exon 5 & g5906C > A, g5907C > G & 15 & 08 & 04 & 15 & 12 \\
\hline Exon 7 & g7320 A > C, g7321_23delTGA & 20 & 03 & 01 & 13 & 11 \\
\hline $3 /$ UTR & g7121_7122insG & 27 & 12 & 07 & 22 & 24 \\
\hline 3 I UTR & g7143delG & 23 & 05 & 02 & 12 & 18 \\
\hline \multirow[t]{3}{*}{ Total } & & 149 & 73 & 30 & 120 & 132 \\
\hline & & \multicolumn{3}{|c|}{$p=0.13$} & \multicolumn{2}{|c|}{$p=0.03$} \\
\hline & & \multicolumn{3}{|c|}{ OR $84.0,95 \% \mathrm{Cl}$ (65.69 to 233.69$)$} & \multicolumn{2}{|c|}{ OR $1.84,95 \% \mathrm{Cl}(1.33-2.54)$} \\
\hline
\end{tabular}

$\mathrm{N}=$ number of cases.

Odd ratio (OR).

$95 \%$ confidence interval (Cl).

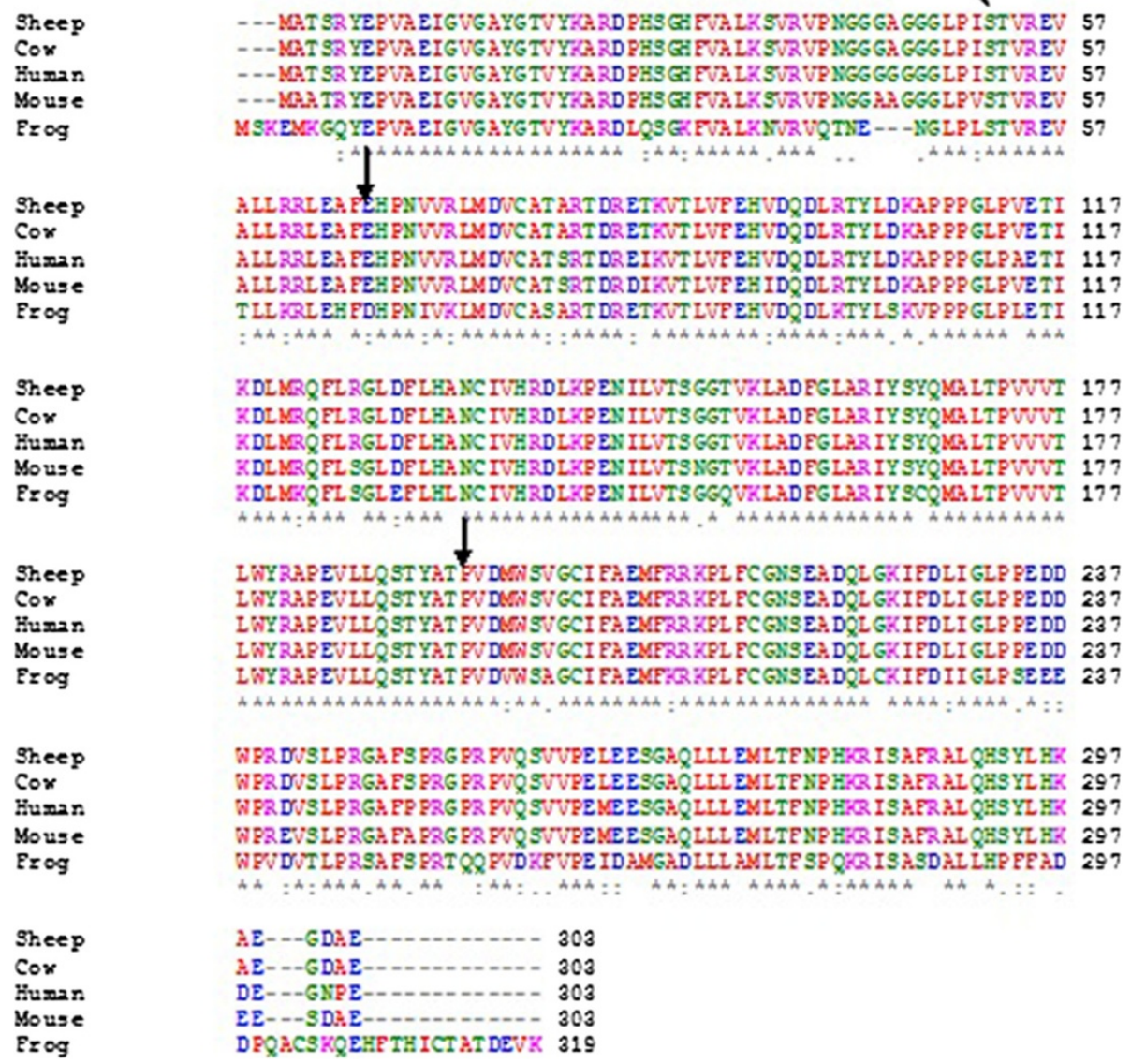

Figure 2 Multiple sequence alignment of CDK4 protein generated with ClustalW 2.1. The locations of two of the point mutations reported here are marked with arrows, and one previously reported mutation, Sequences from five different species were included in the alignment: Human [P11802], mouse [P30285], sheep [B2MVY4] cow bovine [Q32KY4] and frog[Q91727]. 
analyzed a portion of exon 2 of the CDK4, where this mutation mapped by PCR-SSCP and subsequent sequence analysis. Both SSCP and sequence analysis showed that Arg24Cys mutation was not present in any of our cases.

\section{Discussion}

The $\mathrm{Rb}$ pathway has been shown to be frequently altered in human cancers [12-15]. CDK4 is a member of the Ser-Thr protein kinase family and its catalytic domain extends from amino acid 6 to 295. CDK4 consists of eight exons, of which the start codon is located in the beginning of exon 2 and the stop codon in the beginning of exon 8 [16]. Multiple sequence alignment of CDK4 protein was generated with ClustalX, including sequences from five different species was constructed. As shown in Figure 2, the human and sheep cdk4protein sequences have a higher level of identity than the average human-mouse sequence identity ( $97 \%$ versus 94\%).

In present study germline mutational analysis of $C D K 4$ revealed two missense mutations, Ser52Thr and Glu67Gln on exon 2. However, to date, only two mutations in this region, an arginine-to-cysteine missense mutation [17] and an arginine-to-histidine mutation in the germ line of one French melanoma-prone family [6] in codon 24 and 22 have been reported respectively. This mutation at codon 24, as a result of change of a single nucleotide (CGT to TGT) change arginine to cysteine $(\mathrm{R} 24 \mathrm{C})$ is an activating mutation, as it results in growth advantages, because it prevents p16 binding [18]. A prior study found that mutations that decreased cyclin binding of CDK4 by greater than $80 \%$ also decreased kinase activity [19]. Generally, the level of cyclin binding of the various $C D K 4$ mutants correlates well with kinase activity, and the sequences involved in $\mathrm{p} 16^{\mathrm{INK} 4 \mathrm{a}}$ binding are a subset of those involved in cyclin D1 binding [20]. Figure 3 shows In silico structural model analysis of CDK4 protein using the UCSF Chimera 1.5 .3 program revealed that Ser52Thr and Glu67Gln mutations are located in $\mathrm{N}$ terminal domain contain $\alpha \mathrm{C}$ helix (aa 196). That compromise of PISTVRE sequence is important for protein function and binding of cyclin D [21].

In our study three novel frame shift mutations were found on exon 7 and 3/UTR. Frame shift mutation observed in coding region g7321_23delTGA is changing the whole downstream sequence of gene. As a result translation of wrong reading frame continues and the resultant premature RNA stability is compromised so either mRNA will not stable or protein degradation happen [22]. Although genetic alterations in 3/ UTR sequences can modify the binding properties of transacting factors and lead to deregulation in protein production [18]. But most studies have sought to identify

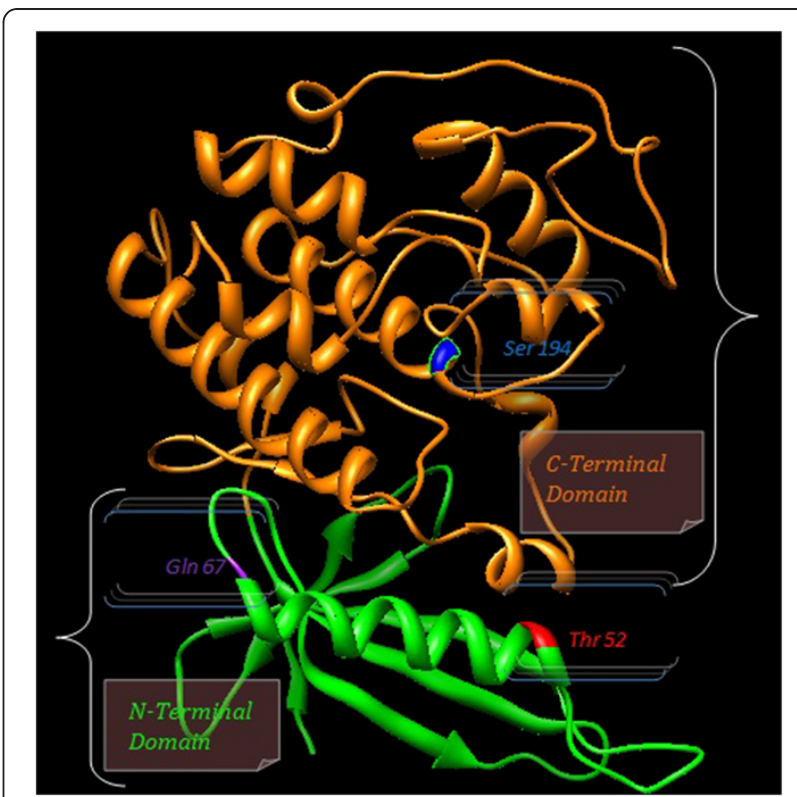

Figure 3 CDK4 protein structure indicating the $\mathrm{N}$-terminal and C-terminal domain. The mutations Ser52Thr, Glu67GIn and Pro194Ser are represented in the structure, using The UCSF Chimera 1.5.3 program.

mutations in the coding region and very few naturally occurring mutations in non coding areas have been described to date. Pakistan harbors vast genetic, ethnic, cultural, social and life style diversity. In present study a group is characterized by onset of cancer frequently before the age of 40 year. Clinically, one key feature of genetic bases of cancer is early age at onset. Similar trends have been reported for familial melanoma, breast and colon cancers. Early disease onset has been associated with an increased prevalence of germline mutations [23].

Amplification and over expression of CDK4 has been detected in sarcoma and glioma, but in carcinoma the picture seems to be unclear. Only sporadic data are available in carcinoma where very low percentage of amplification was reported [24]. CDK4 is altered in melanoma patients by a miscoding mutation (Arg24Cys) that blocks binding of INK4 inhibitors. However, the causal role of these alterations in tumor development is difficult to assess [25]. Present study revealed that there was no germline mutation in codon 24 and 22 of CDK4 and these results support the findings of previous studies $[20,26,27]$. The potentially dominant Arg24Cys mutation of $C D K 4$ was not detected in Indian patients with squamous cell carcinoma of head and neck [8]. CDK4 mutations reported in the literature are rare and little is known about the functional implications of these changes [28]. Study using in vitro site-directed mutagenesis analyzed that disruption of either codon 22 or codon 24 effectively abrogates interaction with cyclin Dl 
and $\mathrm{p} 16^{\mathrm{INK} 4 \mathrm{a}}$ [19]. In vivo analysis of patients with the germ-line Arg24Cys mutation, revealed no documented changes in p16/CDKN2A binding site of CDK4 [29].

\section{Conclusion}

In conclusion Arg24Cys mutation plays a key role in different cancers but in the current study we were unable to detect this mutation. This suggests that CDK4 novel germline mutations observed in study may play a different and important role in squamous cell carcinoma of head and neck cancer in Pakistani population. Potential of these novel mutations in head and neck carcinogenesis need to be explored in order to ascertain there potential importance.

\section{Competing interests}

The authors declare that they have no competing interests.

\section{Authors' contributions}

MS: Study concept and design; acquisition of data; drafting of the manuscript; genetic and bioinformatics analysis; statistical analysis. RMB: Contribution to drafting of the manuscript; interpretation of data. IM: Acquisition of data; collection of samples and interpretation of data. MAK: Study supervision. All authors read and approved the final manuscript.

\section{Acknowledgments}

This study was supported by grants from the higher education commission of Pakistan (HEC). Authors would like to acknowledge the patients and normal individual who contributed to this research work, we also acknowledge hospital staff (National Oncology and Radiotherapy Institute (NORI) and Pakistan Institute of Medical Sciences (PIMS) Islamabad, Pakistan for their cooperation.

Received: 13 March 2012 Accepted: 13 August 2012

Published: 29 August 2012

\section{References}

1. Sherr CJ, McCormick F: The RB and p53 pathways in cancer. Cancer Cell 2002, 2:103-112

2. Malumbres M, Barbacid M: To cycle or not to cycle: a critical decision in cancer. Nat Rev Cancer 2001, 1:222-231.

3. Bockstaele L, Coulonval K, Kooken H: Regulation of CDK4. Cell Div 2006, $1: 25$.

4. Besson A, Assoian RK, Roberts JM: Regulation of the cytoskeleton: an oncogenic function for CDK inhibitors. Nat Rev Cancer 2004, 4:948-955

5. Lantsov D, Meirmanov S, Nakashima M: Cyclin D1 over expression in thyroid papillary microcarcinoma: its association with tumor size and aberrant beta-catenin expression. Histopathology 2005, 47:248-256.

6. Bressac-de-Paillerets B, Avril MF, Chompret A, Demenais F: Genetic and environmental factors in cutaneous malignant melanoma. Biochimie 2002, 84(1):67-74.

7. Goldstein AM, Chan M, Harland M: High-risk melanoma susceptibility genes and pancreatic cancer, neural system tumors, and uveal melanoma across GenoMEL. Cancer Res 2006, 66(20):9818-9828.

8. Tripathi $A B$, Banerjee $S$, Chunder N: Differential alterations of the genes in the CDKN2A-CCND1-CDK4-RB1 pathway are associated with the development of head and neck squamous cell carcinoma in Indian patients. J Cancer Res Clin Oncol 2003, 129:642-650.

9. Vierhapper H, Bieglmayer C, Heinze G, Baumgartner-Parzer SM: Frequency of RET protooncogene mutations in patients with normal and with moderately elevated $(50-100 \mathrm{pg} / \mathrm{ml})$ pentagastrin-stimulated serum concentrations of calcitonin. Thyroid 2004, 14:580-583.

10. Baumgartner-Parzer $S$, Schulze $E$, Waldhäusl W: Mutational spectrum of the steroid 21-hydroxylase gene in Austria: identification of a novel missense mutation. J Clin Endocrinol Metab 2001, 86:4771-4775.
11. Amalio T, Honore N, Cole ST: Detection of mutation in Mycobacteria by PCR-SSCP (Single- Strand Confirmation Polymorphism). Mycobacteria Protocol, Methods Mol Biol 1998, 101:423-443.

12. Koontongkaew S, Chareonkitkajorn L, Chanvitan A: Alterations of p53, pRb, cyclin D1 and cdk4 in human oral and pharyngeal squamous cell carcinomas. Oral Oncol 2002, 36:334-339.

13. Shintani S, Nakahara Y, Mihara M: Inactivation of the p14(ARF), p15(INK4B) and p16(ink4a) genes is a frequent event in human oral squamous cell carcinomas. Oral Oncol 2001, 37:498-504.

14. Hashiguchi $Y$, Tsuda H, Yamamoto K: Combined analysis of p53 and RB pathways in epithelial ovarian cancer. Hum Pathol 2001, 32:988-996.

15. Semczuk A, Jakowicki JA: Alterations of pRb1-cyclin D1-cdk4/6-p16INK4A pathway in endometrial carcinogenesis. Cancer Lett 2004, 203:1-12.

16. Feng G, Qi-cai L, Wang M: Novel mutation of the cyclin-dependent kinase 4 gene in a Chinese patient with intimal sarcoma of the pulmonary artery. Chinese Med J 2009, 122(9):1107-1109.

17. Wolfel T, Hauer M, Schneider J: A p16 INK4a-insensitive CDK4 mutant targeted by cytolytic T lymphocytes in a human melanoma. Science 1995, 269:1281-1284.

18. Jupe ER, Badgett AA, Neas BR: Single nucleotide polymorphism in prohibitin 39 untranslated regions and breast cancer susceptibility. Lancet 2001, 357:1588-1589.

19. Coleman KO, Wautlet BS, Momssey D: Identification of CDK4 sequences involved in cyclin DI and p16 binding. J Biol Chem 1997, 272:1886918874.

20. Mori N, Yang R, Kawamata N: Absence of R24C mutation of the CDK4 gene in leukemias and solid tumors. Int J Hematol 2003, 77:259-262.

21. Day JP, Cleasby A, Tickle J: Crystal structure of human CDK4 in complex with a D-type cyclin. PNAS 2009, 106(11):4166-4170.

22. Indu K: Textbook of medical physiology. UP India: Elsevier; 2009.

23. Tsao H, Zhang X, Kwitkiwski K, Finkelstein MD, Sober AJ, Haluska GF: Low prevalence of germline CDKN2A and CDK4 mutations in patients with early-onset melanoma. Arch Dermatol 2000, 136:1118-1122.

24. Rajakishore M, Bibhu RD: Early overexpression of Cdk4 and possible role of KRF and c-myc in chewing tobacco mediated oral cancer development. Mol Biol Rep 2003, 30:207-213.

25. Malumbres M, Barbacid M: Cell cycle, cdks and cancer: a changing paradigm. Nat Rev Cancer 2009, 9:153-166.

26. Einsiedel HG, Taube T, Beyermann B: Absence of mutations in the CDKN2 binding site of CDK4 in childhood acute lymphoblastic leukemia. Leuk Lymphoma 2001, 40:413-417.

27. Vax W, Bibi R, Diaz-Cano S: Activating point mutations in cyclindependent kinase 4 are not seen in sporadic pituitary adenomas, insulinomas or leydig cell tumours. J Endocrinol 2003, 178:301-310.

28. Goldstein AM, Chidambaram A, Halpern A: Rarity of CDK4 germline mutations in familial melanoma. Melanoma Res 2002, 12:51-55.

29. Zuo L, Weger J, Yang Q: Germline mutations in the $\mathrm{p} 16^{\mathrm{INK} 4 \mathrm{a}}$ binding domain of CDK4 in familial melanoma. Nat Genet 1996, 12:97-99.

doi:10.1186/1897-4287-10-11

Cite this article as: Sabir et al:: Novel germline CDK4 mutations in patients with head and neck cancer. Hereditary Cancer in Clinical Practice 2012 10:11.

\section{Submit your next manuscript to BioMed Central and take full advantage of:}

- Convenient online submission

- Thorough peer review

- No space constraints or color figure charges

- Immediate publication on acceptance

- Inclusion in PubMed, CAS, Scopus and Google Scholar

- Research which is freely available for redistribution 